\title{
INTRODUCTION: DELETION PHENOMENA IN THE MINIMALIST PROGRAM
}

\author{
NoBU GoTO \\ Mie University*
}

In the study of deletion phenomena, the central task of generative grammar has been to explain the following issues:

(1) What is the nature of the identity condition?

(2) How is a deletion site licensed in the syntax?

With respect to (1), which we may call the Identification Problem, it has been customary to assume since Ross (1969) that a deleted constituent must be identical to its antecedent not only semantically but also syntactically. With respect to (2), on the other hand, which we may call the Licensing Problem, it has standardly been assumed since Lobeck (1990) that a deletion site must be the complement of a functional head that agrees with its specifier.

Although the previous approaches seem to be on the right track, the issues are not completely settled. Specifically, since Merchant (2001) develops a theory which allows deletion even if a deleted constituent and its antecedent have different syntactic structures, as long as they are semantically identical to each other, there has been a lot of controversy about the nature of the identity in question. Likewise, since Chomsky (1993) proposes the minimalist program (MP) that entirely eliminates the notion of Spec-Head Agreement, the problem of licensing has also remained unclear. Therefore, it is quite significant to examine deletion phenomena from various minimalist points of view and attempt to provide a principled account for them.

For this reason, four articles are brought together in the name of "Deletion Phenomena in the Minimalist Program" with an aim to bring new insight into the long-standing issues: Nakamura's Article ("Semantic Identity

* I would like to thank anonymous EL reviewers and the participants of the workshop held at the 30th Annual Meeting of the English Linguistic Society of Japan at Keio University on November 10-11, 2012 for their significant comments and suggestions. 
and Deletion"), Takita's Article ("Antecedent-Contained Sluicing and Identity in Ellipsis"), Kimura's Article ("Phonological Adjacency as a Trigger of Movement"), and Goto's Article ("Deletion by Phase and Its Contribution to Non-Constituent Deletion"). The former two articles address the identification problem, and the latter two the licensing problem. In what follows, I introduce each article, one by one, in this order.

Nakamura's Article claims that deletion is insensitive to voice and category mismatches by providing several counter examples to Merchant (2008, 2013), who argues that VP-Deletion, Pseudogapping, and Sluicing are sensitive to voice mismatches, and Tanaka (2011), who argues that VP-Deletion and Sluicing are sensitive to category mismatches. He proposes an alternative semantic account for the relevant data without recourse to syntactic identity conditions. Also, in addition to various counter-examples, he develops a conceptual argument against Merchant's and Tanaka's approaches in terms of the MP. Hence, the empirical and conceptual arguments offered by this article will pose significant challenges for a theory of deletion that assumes syntactic identity conditions.

Takita's Article also explores the nature of identity in ellipsis, dealing with so-called Antecedent-Contained Sluicing, where the antecedent of the sluiced clause appears to properly contain the deletion site. Based on a new set of data from English, German and Russian, which shows that syntactic identity is required to capture the properties of the construction in question, he proposes an analysis that tries to maintain the purely syntactic identity-based approach. Therefore, the new findings in this article will not only give support to syntactic identity-based approach but also give rise to a serious challenge to a theory of deletion that does not assume syntactic identity conditions.

Kimura's Article investigates licensing conditions on Sluicing. To license the relevant site, i.e. TP, it has traditionally been assumed that a wh-category occupies SPEC-CP. However, she, crucially departing from the traditional point of view, proposes that the wh-category can stay inside TP. Following Agbayani and Ochi's (2006) theory of movement and global economy, she argues that wh-category movement is triggered solely by the PF Adjacency Condition, which demands that a wh-feature and its category be adjacent to each other, and claims that if deletion can create the required adjacency, wh-category movement ceases to apply for economy reasons under the assumption that deletion can affect non-constituents. It will turn out that the non-movement analysis of Sluicing can straightforwardly account for unique properties of Multiple Sluicing and Swiping-related phe- 
nomena.

Goto's Article also concerns the licensing problem and attempts to formalize a mechanism of deletion in terms of the recent minimalist development-Cyclic Spell-Out and local economy (Chomsky (2000)). Specifically, to license a deletion site, he puts forward the Deletion by Phase Hypothesis (DBPH), according to which deletion can optionally apply phase by phase. Specifically, following Takahashi (2002), he assumes that only complements of phase heads, i.e. a Spell-Out domain, can undergo deletion, and proposes that whether a Spell-Out domain is pronounced or deleted is determined upon Spell-Out. As a consequence of this hypothesis, it turns out that Gapping can be derived without appealing to the movement of the remnant assumed in Johnson (2009) and others.

As readers might notice, there are several places where the crucial conclusions or background hypotheses conflict with each other. For example, while Nakamura's Article claims that deletion is insensitive to voice mismatch in many instances of deletion, Takita's Article argues that it is sensitive to syntactic identity at least in Antecedent-Contained Sluicing; and while Kimura's Article assumes a kind of global economy to compare two convergent derivations in terms of deletion and category movement, Goto's Article tries to deal with deletion in terms of local economy. Though the conclusions may be different among these papers, the authors refer to the others' papers in relevant respects, so we hope that each article shows as clearly as possible what underlies those conflicts and also delineates a certain direction to go for further exploring deletion phenomena.

Finally, it is probably helpful to see how the four articles view the following issue:

(3) Is ellipsis a result of PF-deletion or LF-copying?

In addition to the two main issues (1) and (2), there is a long-standing problem of whether ellipsis should be understood in terms of PF-deletion or LF-copying. With respect to this issue, while Nakamura's Article and Takita's Article stand neutral, Kimura's Article and Goto's Article make crucial use of PF-deletion. Hence, our arguments are arguably consistent with the PF-deletion approach rather than LF-copying approach. Nonetheless, whatever the ultimate fate of ellipsis may be, there is absolutely no doubt that the four articles provide a new set of data and arguments that the LF-copying approach cannot ignore. Therefore, our project will benefit not only the proponents of PF-deletion but also those who pursue LF-copying.

None of the issues are resolved, and there are still many issues untouched in this project. However, it would be no exaggeration to say that this proj- 
ect undoubtedly introduces a breath of fresh air into the old issues of identity and licensing from various minimalist points of view. We ardently hope that our effort will bear fruit in the future and stir readers' imaginations to deepen our understanding about the nature of the issues. Only time will tell if our contribution is to be justified.

\title{
REFERENCES
}

Agbayani, Brian and Masao Ochi (2006) "Move F and PF/LF Defectiveness," Minimalist Essays, ed. by Cedric Boeckx, 19-34, John Benjamins, Amsterdam.

Chomsky, Noam (1993) "A Minimalist Program for Linguistic Theory," The View from Building 20: Essays in Linguistics in Honor of Sylvain Bromberger, ed. by Ken Hale and Samuel J. Keyser, 1-52, MIT Press, Cambridge, MA.

Chomsky, Noam (2000) "Minimalist Inquiries: The Framework," Step by Step: Essays on Minimalist Syntax in Honor of Howard Lasnik, ed. by Roger Martin, David Michaels and Juan Uriagereka, 89-155, MIT Press, Cambridge, MA.

Johnson, Kyle (2009) "Gapping is Not (VP-) Ellipsis," Linguistic Inquiry 40, 289328.

Lobeck, Ann (1990) "Functional Heads as Proper Governors," NELS 20, 348-362.

Merchant, Jason (2001) The Syntax of Silence: Sluicing, Islands and the Theory of Ellipsis, Oxford University Press, Oxford.

Merchant, Jason (2008) "An Asymmetry in Voice Mismatches in VP-Ellipsis and Pseudogapping," Linguistic Inquiry 39, 169-179.

Merchant, Jason (2013) "Voice and Ellipsis," Linguistic Inquiry 44, 77-108.

Ross, John R. (1969) "Guess Who?” CLS 5, 252-286.

Tanaka, Hidekazu (2011) "Syntactic Identity and Ellipsis," The Linguistic Review 28, 79-110.

Takahashi, Daiko (2002) "Feizu no Risaikuru (Recycling Phases)," Eigo Seinen (The Rising Generation) 148, 270-273.

[received April 25, 2013, revised and accepted August 9, 2013]

\author{
Liberal Arts Center \\ Mie University \\ 1577 Kurimamachiya-cho, Tsu-shi \\ Mie 514-8507 \\ e-mail: goto.nobu@mie-u.ac.jp
}

